\title{
Evidence for substantial intramolecular heterogeneity in the stable carbon isotopic composition of phytol in photoautotrophic organisms
}

\author{
Stefan Schouten ${ }^{1 *}$, Suat Özdirekcan ${ }^{1,2}$, Marcel T.J. van der Meer ${ }^{1}$, Peter Blokker ${ }^{1,3}$, \\ Marianne Baas ${ }^{1}$, John M. Hayes ${ }^{4}$ and Jaap S. Sinninghe Damsté ${ }^{1}$
}

1. Netherlands Institute for Sea Research, Department of Marine Biogeochemistry \& Toxicology, PO Box 59, 1790 AB Den Burg, Texel, The Netherlands.

2. Present address: Department of Biochemistry of Membranes, University of Utrecht, Padualaan 8, 3584 CH Utrecht, The Netherlands.

3. Present address: Nalco Europe B.V. PO Box 627, 2300 AP Leiden, The Netherlands.

4. Woods Hole Oceanographic Institute, MS 8, Woods Hole, MA 02543, USA.

*: corresponding author: E-mail : schouten@ nioz.nl; Tel. (+31) (0)222 369546; Fax: (+31) (0)222-319674.

Revised version submitted to Organic Geochemistry

Keywords: phytol, phytane, pristane, stable carbon isotope, mevalonic acid pathway, 2-C-methylerythritol-4-phosphate pathway, 2,6,10-trimethylpentadecan-2-one. 


\begin{abstract}
The ubiquitous isoprenoid phytol was isolated from a range of algae, terrestrial plants and a bacterium and its two terminal carbon atoms were quantitatively removed by chemical oxidation. The product, 6,10,14-trimethylpentadecan-2-one, was depleted in ${ }^{13} \mathrm{C}$ by $1-4 \%$ relative to the parent phytol. This difference is significant, and indicates that the pathway for biosynthesis of phytol induces substantial intramolecular stable carbon isotopic fractionations. The nature and magnitude of the fractionations suggest strongly that it is associated both with the biosynthesis of isopentenyl pyrophosphate via the 2-C-methylerythritol-4-phosphate pathway and with the formation of carotenoids and phytol from geranyl-geraniolphosphate. As a result of these large, intramolecular isotopic differences, diagenetic products formed by loss of $\mathrm{C}$, such as pristane, may be naturally depleted in ${ }^{13} \mathrm{C}$ by several permil relative to phytane.
\end{abstract}

\title{
1. Introduction
}

The isotopic compositions of individual lipids in sediments and organisms depend strongly on the isotopic compositions of their biosynthetic precursors and on the pathways by which they are biosynthesized (Hayes, 1993; 2001). Variations in these factors can lead to isotopic compositions differing by up to $20 \%$ o between lipids within a single organism (e.g. Summons et al., 1994; Schouten et al., 1998b; Sakata et al., 1997; van der Meer et al., 1998; summarized by Hayes, 2001). However, the mechanisms causing this isotopic diversity are incompletely understood (Hayes, 2001).

A few studies have focused on the influence of the enzyme pyruvate dehydrogenase on the isotopic composition of lipids (Monson and Hayes, 1982a; Melzer and Schmidt, 1987). These showed that this enzyme discriminates against ${ }^{13} \mathrm{C}$ 
during the decarboxylation of pyruvate to produce acetyl coenzyme A. At least in bacteria, this isotopic fractionation accounts for the relative depletion of ${ }^{13} \mathrm{C}$ in straight-chain lipids (additional fractionations are evident in eukaryotes; Monson and Hayes, 1982b). Acetyl coenzyme A can also serve as a precursor for isoprenoid lipids (Ratledge and Wilkinson, 1989). The isotopic compositions of those products indicate that fractionations are associated with the biosynthesis of isoprenoids, e.g. within photosynthetic algae isoprenoid lipids are isotopically depleted compared to biomass (Schouten et al., 1998b).

Phytol is thought to be one of the main precursors of the ubiquitously occurring sedimentary compounds pristane and phytane (e.g. Volkman and Maxwell, 1984 and references cited therein; Koopmans et al., 1999). The diagenesis of phytol has been studied extensively over the last decades and the carbon isotopic compositions of phytol or its diagenetic products have often been used as indicators of the carbon isotopic composition of photoautotrophic organic carbon (e.g. Freeman et al., 1989; Hayes et al., 1990; Kohnen et al., 1992; Grice et al. 1998; Koopmans et al., 1999; Schouten et al., 2000a).

Isopentenyl pyrophosphate (IPP), the biomonomer from which phytol is assembled (e.g. Ratledge and Wilkinson, 1989; Fig. 1), can be biosynthesized via two different pathways using different precursors. In some cases, IPP is biosynthesized from three acetyl coenzyme A units. Because mevalonic acid is an important intermediate product, this route (Fig. 1; e.g. Nes and McKean, 1977) is known as the mevalonic acid (MVA) pathway. Alternatively, IPP is biosynthesized from pyruvate and glyceraldehyde-3-phosphate with 1-deoxyxylulose 5-phosphate and 2-Cmethylerythritol-4-phosphate (MEP) as important intermediates (Rohmer et al., 1993; 1996; Bach, 1995; Lichtenthaler et al., 1997; Lichtenthaler, 1999; Schwender et al., 
2001; Eisenreich et al., 2004; Fig. 1). This so-called MEP-pathway is now thought to be widespread in Bacteria (Lichtenthaler, 1999; Eisenreich et al., 2004) whilst in Eukaryotes the MEP pathway is mainly operating in the chloroplast to produce isoprenoids such as phytol (Schwender et al., 2001; Eisenreich et al., 2004; Rohmer, 2007). To produce regular isoprenoids with 20 or 40 carbon atoms, 4 IPP units are sequentially coupled and the product, geranyl-geraniolphosphate (GGP), is subsequently fed into different biosynthetic pathways to produce metabolic products like quinones, tocopherols, carotenoids and phytol (Fig. 1).

The different pathways for IPP biosynthesis produce isoprenoids with differing depletions of ${ }^{13} \mathrm{C}$ relative to total biomass (e.g. Hayes, 2001; Massé et al., 2004). The reasons for this are not known in detail, but are likely to include differing intramolecular distributions of ${ }^{13} \mathrm{C}$. If any such isotopic patterns can be determined, they will not only explain quantitatively the intermolecular isotopic differences, but also point to the specific biosynthetic steps which are responsible for them (cf. Monson and Hayes, 1982a). Here we report here on intramolecular stable carbon isotopic differences within phytol determined using a novel approach involving the selective oxidation of carbon $\mathrm{C} 1$ and $\mathrm{C} 2$ from phytol.

\section{Materials and methods}

\subsection{Cultures}

The algae and conditions of growth are listed in Table 1. Continuous cultures were grown in constantly aerated, 3-1 Erlenmeyer flasks and were illuminated using a 16:8 $\mathrm{h}$ light/dark regime. Dilution rates ranged between $0.13-0.22 \mathrm{~d}^{-1}$ except for Dunaliella $\left(0.50 \mathrm{~d}^{-1}\right)$. Most marine algae were grown on an F/2 medium (Guillard, 1975) with the exception of the dinoflagellates which were grown using a medium described 
by Hansen (1989). Freshwater species were grown using a 16:8 h light/dark regime and a medium described by Kates and Jones (1964). Batch cultures were harvested when the algae reached the end of their exponential-growth phase. Euglena gracilis strain $\mathrm{Z}$ (Klebs 1224-5/25) was obtained from Algensammlung Göttingen and was grown autotrophically under axenic conditions with a light/dark regime of 14:10 h. Every three days, at the end of a dark period, the culture was diluted: $10 \mathrm{ml}\left(0.5 \times 10^{6}\right.$ cells $\left./ \mathrm{ml}\right)$ of the suspension was transferred to 100-ml fresh medium (Cramer and Myers, 1952).

Chloroflexus aurantiacus OK-70fl (DSM 636) was grown under anaerobic phototrophic conditions at $55^{\circ} \mathrm{C}$ using a mineral-salt medium supplemented with vitamins and gassed with a mixture of $\mathrm{H}_{2} / \mathrm{CO}_{2}$ (80:20; Menendez et al., 1999). Cells were harvested during the exponential-growth phase by centrifugation and subsequently frozen in liquid nitrogen and lyophilized before lipid extraction.

The terrestrial plants were obtained from the peat bog reserve "Bargerveen", (Zwartemeer, SE-Drenthe, The Netherlands), except Ficus benjamini which was grown as a house plant in an office under natural sunlight.

\subsection{Isotopic analysis of phytol}

The freeze-dried cell material was ultrasonically extracted with methanol $(\mathrm{MeOH} ; 2 \mathrm{x}), \mathrm{MeOH} /$ dichloromethane $(1: 1, \mathrm{v} / \mathrm{v} ; 2 \mathrm{x})$ and dichloromethane $(2 \mathrm{x})$. The extracts were subsequently saponified by refluxing (1h) with a $1 \mathrm{~N} \mathrm{KOH} / \mathrm{MeOH}$ solution. After neutralising to $\mathrm{pH} 3$ with a $2 \mathrm{~N} \mathrm{HCl} / \mathrm{MeOH}$ solution, the samples were washed with double-distilled water/DCM $(2: 3 \mathrm{v} / \mathrm{v})$ and then twice extracted with DCM in a separatory funnel. Subsequently, the DCM layers were combined and dried by filtering through a column of anhydrous $\mathrm{Na}_{2} \mathrm{SO}_{4}$. Alcohols present in the extract

were isolated by column chromatography $\left(\mathrm{Al}_{2} \mathrm{O}_{3}\right)$ using a 9:1 (v/v) mixture of $n$ - 
hexane and DCM to elute the apolar compounds and 1:1 (v/v) DCM/MeOH to obtain the alcohol fraction. The alcohol fraction was then silylated by adding $75 \mu 1$ of BSTFA and pyridine and heating the mixture at $60^{\circ} \mathrm{C}(30 \mathrm{~min})$. To correct for the isotopic change due to the introduction of carbon derived from the trimethylsilyl (TMS) group, a hexadecanol standard with an known isotopic composition (-30.1\%o), was silylated using the same batch of BSTFA. By determining the carbon isotopic composition of the derivatized standard, the carbon isotopic composition of the TMS group was calculated by mass balance. As discussed below, the required correction for the presence of TMS carbon introduces an additional uncertainty in the isotopic composition of phytol. The fractions were analysed by gas chromatography (GC), GC-combustion-isotope ratio monitoring mass spectrometry (GC-C-irms) and, in some instances, by GC-mass spectrometry (GC-MS).

\subsection{Oxidation of phytol}

To convert phytol into 6,10-14-trimethylpentadecan-2-one, portions of the silylated extracts were oxidized using $\mathrm{RuO}_{4}$ (Schouten et al, 1998a). Prior to oxidation, the solvent in which the alcohol fractions was stored was evaporated under dry $\mathrm{N}_{2}$ and the fractions were dissolved in $2 \mathrm{ml}$ of $1: 1(\mathrm{v} / \mathrm{v})$ chloroform/acetonitrile. An equal volume of an aqueous solution of $0.2 \mathrm{M} \mathrm{NaIO}_{4}$ at $\mathrm{pH} 4$ was then added. The reaction was started in an ultrasonic bath by adding $6 \mathrm{mg}$ of $\mathrm{Ru}(\mathrm{III})$ as a catalyst. The reaction was stopped by adding $3 \mathrm{ml}$ of double-distilled water and $2 \mathrm{ml}$ of $n$-hexane, followed by centrifugation to remove the residual material from the organic layer. The organic layer was then removed and added to $0.5 \mathrm{ml}$ of $\mathrm{MeOH}$. Subsequently, the remaining Ru salts were extracted with $2 \mathrm{ml}$ of $n$-hexane and twice with $2 \mathrm{ml}$ of ethyl acetate. The black $\mathrm{Ru}$ salts were then precipitated from the organic layer by 
centrifugation as described above and the remaining supernatant was washed with 0.5 $\mathrm{ml}$ of a $5 \%(\mathrm{w} / \mathrm{v})$ solution of sodium thiosulfate in water. The extract was dried over anhydrous $\mathrm{Na}_{2} \mathrm{SO}_{4}$ and evaporated to dryness under nitrogen. The dried residue was finally dissolved in ethyl acetate and analyzed by GC-FID, GC-MS and irm-GCMS.

\subsection{Analytical methods}

A Hewlett Packard 5890 series II chromatograph equipped with an on-column injector and fitted with a $25 \mathrm{~m} \times 0.32 \mathrm{~mm}$ fused silica capillary column coated with

CP-Sil 5 (film thickness $0.12 \mu \mathrm{m}$ ) was used for separations and analyses. Helium was used as carrier gas and the oven was programmed from $70^{\circ} \mathrm{C}$ to $130^{\circ} \mathrm{C}$ at $20^{\circ} \mathrm{C} / \mathrm{min}$, followed by an increase of $4^{\circ} \mathrm{C} / \mathrm{min}$ to $320^{\circ} \mathrm{C}$ (15 min hold time). Compounds were detected using a flame ionization detector.

Samples were analyzed by GC-MS using the GC conditions described above. The column was directly inserted into the electron-impact ion source of a VG Autospec Ultima mass spectrometer operated with a mass range of $m / z 40-800$, a cycle time of $1.8 \mathrm{~s}$, and an ionization energy of $70 \mathrm{eV}$.

The DELTA-C irm-GCMS-system has been described previously (Schouten et al., 1998b). The gas chromatograph was equipped with a fused silica capillary column (25 $\mathrm{m} \times 0.32 \mathrm{~mm}$ ) coated with CP Sil-5 (film thickness $=0.12 \mu \mathrm{m}$ ) with helium as carrier gas. The samples (dissolved in ethyl acetate) were on-column injected at $70^{\circ} \mathrm{C}$. The column temperature was programmed to $130^{\circ} \mathrm{C}$ at $20^{\circ} \mathrm{C} / \mathrm{min}$, then to $320^{\circ} \mathrm{C}$ at $4^{\circ} \mathrm{C} / \mathrm{min}$, and finally held at $320^{\circ} \mathrm{C}$ for $30 \mathrm{~min}$. Values of $\delta^{13} \mathrm{C}$ for individual peaks of $\mathrm{CO}_{2}$ resulting from combustion of the eluted compounds were calculated from integrated ion currents at masses 44, 45 and 46 (Ricci et al., 1994). The $\delta$ scale was calibrated using 
$\mathrm{CO}_{2}$ spikes produced by admitting $\mathrm{CO}_{2}$ with a known ${ }^{13} \mathrm{C}$-content at regular intervals. Performance of the combustion system was checked by regularly injecting a $C_{20}$ and $C_{24}$ perdeuterated n-alkane mixture and results were always within $0.5 \%$ of values determined offline. The reported $\delta$ values are the averages of at least two analyses. Isotopic compositions are reported relative to the VPDB ${ }^{13} \mathrm{C}$ standard.

To assess precision, we calculated the pooled standard deviations of replicate analyses. These were $0.56 \%$ o for phytol (51 replicates and 19 mean values, thus 32 degrees of freedom) and $0.46 \%$ o for the $\mathrm{C}_{18}$ ketone (58 replicates, 19 means, 39 degrees of freedom). This assessment of precision attributes variations mainly to random analytical errors rather than to sample-specific factors (e.g., coelutions). It allows large sample-vs.-mean differences to influence strongly the estimate of the standard deviation and is therefore a conservative assessment. Inspection of the chromatograms and sets of replicates supports these choices. Accordingly, to assign uncertainties to analytical results, we have taken $0.5 \%$ as the standard deviation of a single isotopic analysis and computed the standard deviation of the mean by dividing $0.5 \%$ by the square root of the number of replicates.

In the case of phytol, correction for the additional carbon present in the analyzed,TMS ether slightly increases the uncertainty. Specifically,

$$
\sigma_{\mathrm{Ph}}^{2}=\left(\frac{23}{20}\right)^{2} \sigma_{\mathrm{Ph}-\mathrm{TMS}}^{2}+\left(\frac{3}{20}\right)^{2} \sigma_{\mathrm{TMS}}^{2}
$$

where the $\sigma$ terms are standard deviations of the calculated $\delta$ value of phytol (Ph), the measured $\delta$ value of the TMS ether of phytol (Ph-TMS), and the $\delta$ value of TMS calculated from the analysis of the TMS ether of the hexadecanol isotopic standard (TMS). The coefficients 23, 20, and 3 are the numbers of carbon atoms in the TMS ether of phytol, in phytol, and in the TMS moiety. For $\sigma_{\mathrm{TMS}}=1.6 \%$ (pertinent in this 
case), $\sigma_{\mathrm{Ph}}$ is $0.62 \%$ (vs. $0.5 \%$ o for an analysis not requiring TMS correction) for a single analysis, $0.47 \%$ (vs. $0.35 \%$ ) for a duplicate, $0.41 \%$ (vs. $0.29 \%$ ) for a triplicate, and $0.37 \%$ (vs. $0.25 \%$ ) for a quadruplicate. Hence, the uncertainty in the isotopic composition of phytol is only slightly increased by the correction for the TMSderivitization.

\section{Results}

\subsection{Isotopic fractionations associated with the analytical method}

Our method to examine intramolecular isotopic differences in phytol involves the treatment of phytol with $\mathrm{RuO}_{4}$ to form 6,10-14-trimethylpentadecan-2-one (Fig. 2). This reaction removes carbon atoms $\mathrm{C} 1$ and $\mathrm{C} 2$. Provided that either isotopic fractionation is absent or that the oxidation reaction is quantitative, resulting in net zero fractionation, comparison of the isotopic composition of the $\mathrm{C}_{18}$ ketone with that of phytol then provides information about the distribution of ${ }^{13} \mathrm{C}$ within phytol. To determine the reaction's isotopic characteristics, a mixture of $E$ - and Z-phytol produced by Aldrich Chemical Company (St. Louis, MO), was oxidized in four replicate experiments. The average yield was $100 \pm 4 \%$ and $6,10-14$ trimethylpentadecan-2-one was the sole product (Fig. 2).

Isotopic analyses showed that the isotopic compositions of the oxidation product and of the commercial phytol were identical (Table 2). Two factors now combine. First, isotopic fractionation should be absent because the yield is quantitative. Second, isotopic homogeneity is likely because of the mixed origin of the phytol produced by Aldrich. Together, these support the conclusion that the procedure

provides an accurate view of the isotopic difference between $\mathrm{C} 1+\mathrm{C} 2$ and the remainder of the phytol molecule. 
To test the reproducibility of the method, cells of Tetraedron minimum grown in continuous culture were divided in two parts and analyzed separately. For these replicates, the isotopic differences between phytol and its oxidation product did not differ significantly (1.6 versus $2.1 \%$; Table 2$)$. This indicates that the isotopic differences measured with the $\mathrm{RuO}_{4}$ oxidation method are reproducible. Additionally, these isotopic differences, derived from a continuous culture of $T$. minimum, do not differ significantly from the isotopic differences observed for a batch culture of $T$. minimum (1.6\%o; Table 2). This suggests that the methods used here have no substantial effects on the intramolecular distribution of ${ }^{13} \mathrm{C}$ in phytol.

\subsection{Isotopic variations in natural phytol}

To begin intramolecular isotopic studies of isoprenoids, we have used the procedure described above to survey the isotopic characteristics of phytol from a variety of sources. These include cultures of seven marine and five freshwater algae, specimens of four terrestrial plants, and a culture of a photosynthetic bacterium (Table 2). As a plastidic product, phytol will in nearly all cases have been produced by the MEP pathway (possible exceptions are discussed below). The results bear on two questions. First, is there a consistent isotopic signal that might be linked to biosynthetic processes? Second, considering possible instances of synthesis via the MVA pathway, is there any evidence that the isotopic characteristics of the MEP and MVA pathways differ significantly?

Results are summarized in Table 2. The answer to the first question is readily apparent. Even though uncertainties are appreciable relative to the isotopic differences, the $\mathrm{C}_{18}$ ketone is in all cases significantly depleted in ${ }^{13} \mathrm{C}$ relative to the phytol from which it was derived. Accordingly, carbon positions $\mathrm{C} 1$ and $\mathrm{C} 2$ are on 
average enriched in ${ }^{13} \mathrm{C}$ relative to the average of the 18 other carbon positions in the parent phytol.

\section{Discussion}

\subsection{Mechanisms and magnitudes of fractionation}

The origins of the isotopic signal can be considered systematically. We start from the consistent observation that phytol is depleted in ${ }^{13} \mathrm{C}$ relative to average biomass (cf. Schouten et al., 1998b). The fractionations responsible for that overall depletion must occur during the production of the IPP from which phytol is produced. It is therefore possible, even likely, that the isotopic difference examined in these analyses derives from an isotopic pattern within IPP, namely ${ }^{13} \mathrm{C}$-enrichment of the average $\delta^{13} \mathrm{C}$ of $\mathrm{C} 1$ and $\mathrm{C} 2\left(\overline{\delta_{\mathrm{t}}}\right)$ relative to the average $\delta^{13} \mathrm{C}$ of $\mathrm{C} 3, \mathrm{C} 4$, and $\mathrm{C} 5\left(\overline{\delta_{\mathrm{h}}}\right.$; Fig. 2). This corresponds to $\Delta_{\mathrm{i}}>0$ where $\Delta_{\mathrm{i}} \equiv \overline{\delta_{\mathrm{t}}}-\overline{\delta_{\mathrm{h}}}$. Given the limitations imposed by the present analytical scheme, however, an alternative possibility must be considered. Specifically, even if strong isotopic order is present within IPP and underlies the overall depletion of ${ }^{13} \mathrm{C}$ in phytol, it is conceivable that $\Delta_{\mathrm{i}}=0$ (n. b., $\overline{\delta_{\mathrm{t}}}$ and $\overline{\delta_{\mathrm{h}}}$ are average isotopic compositions, $\Delta_{\mathrm{i}}=0$ therefore does not exclude all forms of intramolecular isotopic order). In that case, the isotopic differences measured in the present investigation would derive from enrichment of ${ }^{13} \mathrm{C}$ only at positions $\mathrm{C} 1$ and C2 in phytol and not in other isoprenoids derived from IPP.

Distinct mechanisms are associated with these cases. In the first, the isotopic differences measured here derive from isotope effects and carbon flows associated with the production of IPP. In the second, they derive from some process downstream from production of IPP. Since a significant branch point in flows of carbon is 
required, a single possibility for downstream fractionation exists, namely the commitment of GPP either to production of phytol or dimerization to yield phytoene and, subsequently, carotenoids (Fig. 1). At that point, if the kinetic isotope effect on the branch leading to phytoene is larger than that on the branch leading to phytol, an enrichment at position $\mathrm{C} 1$ in phytol would result ( $\mathrm{C} 2$ would be largely unaffected; the enrichment measured here for $\mathrm{C} 1+\mathrm{C} 2$ would in fact be concentrated at $\mathrm{C} 1$ ). We use $\Delta_{\mathrm{g}}$ to designate this enrichment. Mass-balance expressions are then as follows:

$$
\begin{gathered}
20 \overline{\delta_{\mathrm{P}}}=12 \overline{\delta_{\mathrm{h}}}+7 \overline{\delta_{\mathrm{t}}}+1\left(\overline{\delta_{\mathrm{t}}}+\Delta_{\mathrm{g}}\right) \\
18 \overline{\delta_{\mathrm{K}}}=12 \overline{\delta_{\mathrm{h}}}+6 \overline{\delta_{\mathrm{t}}}
\end{gathered}
$$

Equation 2 relates the average isotopic composition of the carbon positions in phytol to those of the carbon positions in the head and tail portions of IPP and allows for one of the carbon positions (namely $\mathrm{C} 1$ in phytol) to be enriched by a further amount, i.e. $\Delta_{\mathrm{g}}$. Equation 3 notes that the 18 carbon atoms in the ketone produced by oxidation of phytol are comprised of 12 carbon atoms from the head and 6 from the tail of IPP. Substituting $\overline{\delta_{\mathrm{t}}}=\overline{\delta_{\mathrm{h}}}+\Delta_{\mathrm{i}}, \Delta_{\mathrm{P}-\mathrm{K}} \equiv \overline{\delta_{\mathrm{P}}}-\overline{\delta_{\mathrm{K}}}$, and combining equations 2 and 3, we obtain

$$
20 \Delta_{\mathrm{P}-\mathrm{K}}=\frac{4}{3} \Delta_{\mathrm{i}}+\Delta_{\mathrm{g}}
$$

This equation relates the isotopic difference between phytol and the $\mathrm{C}_{18}$ ketone (Table 2) to isotopic differences between the head and tail portions of IPP and to enrichment of ${ }^{13} \mathrm{C}$ at $\mathrm{C} 1$ in phytol. It shows how either of the mechanisms suggested above, or a combination of them, could account quantitatively for the observed isotopic differences. The situation is summarized in Figure 3. In the case of $\Delta_{\mathrm{P}-\mathrm{K}}=1.5 \%$ o, for example, the observation might be explained by $\Delta_{\mathrm{i}}=22.5 \%$ and $\Delta_{\mathrm{g}}=0 \%$, by $\Delta_{\mathrm{i}}=0 \%$ o and $\Delta_{\mathrm{g}}=30 \%$, or by any combination of values of $\Delta_{\mathrm{i}}$ and $\Delta_{\mathrm{g}}$ on the line linking these points. 
Intramolecular isotopic differences observed up to now (Abelson and Hoering, 1961; Monson and Hayes, 1982a; b) have not exceeded 25\%o. If a slightly greater value, $30 \%$, is taken as a plausible maximum value for fractionation at a single $\mathrm{C}$ position in a multi-C reactant, Figure 3 shows that $\Delta_{\mathrm{i}}$ alone (i.e., $\Delta_{\mathrm{g}}=0$ ) can explain only $\Delta_{\mathrm{P}-\mathrm{K}} \leq 2 \%$ o. Similarly, $\Delta_{\mathrm{g}}$ alone can explain only $\Delta_{\mathrm{P}-\mathrm{K}} \leq 1.5 \%$. For six of the entries in Table 2 (S. communis, P. boryanum, Tetraselmis sp., Amphidinium sp., $S$. recurvum, and $F$. benjamini), a combination of both fractionations is required even at the lower end of the $95 \%$ confidence interval for the observed value of $\Delta_{\mathrm{P}-\mathrm{K}}$. Thus, both mechanisms are likely responsible for the observed differences between phytol and the $\mathrm{C}_{18}$ ketone. These mechanisms will be discussed in more detail below.

\subsubsection{Fractionation during IPP biosynthesis}

Values of $\Delta_{\mathrm{i}}$ indicated in Figure 3 must be associated with the MEP pathway, which is predominant in chloroplasts (Lichtenthaler et al., 1997; Schwender et al., 2001; Eisenreich et al., 2004). A notable exception is phytol biosynthesized by Chloroflexus aurantiacus which has a substantially smaller difference. This will be discussed in more detail below.

Close examination of the MEP pathway (Fig. 1) reveals an important branch point: the decarboxylation of pyruvate to form activated acetaldehyde that subsequently reacts with glyceraldehyde phosphate (GAP). Previous studies have shown that decarboxylation of pyruvate during the biosynthesis of acetyl coenzyme A leads to a depletion in ${ }^{13} \mathrm{C}$ of the carboxyl group (Monson and Hayes, 1982a; Melzer and Schmidt, 1987). The decarboxylation reaction in the MEP pathway (Fig. 1) is similar and the potentially-depleted carbon position can be traced to C3 in IPP. Other carbon atoms in the IPP formed via the MEP pathway have not been affected by 
decarboxylation reactions and thus may be less depleted in ${ }^{13} \mathrm{C}$. In fact, carbon atoms $\mathrm{C} 1$ and $\mathrm{C} 2$ have potentially been unfractionated during synthesis of IPP by the MEP pathway since they have not been involved in any carbon-carbon bond cleavages. Thus, based on current knowledge of the MEP pathway, we predict that C3 is depleted in ${ }^{13} \mathrm{C}$ compared to the other carbon atoms in IPP. This fits with the observed data, i.e. ${ }^{13} \mathrm{C}$-depletion of $\mathrm{C} 3+\mathrm{C} 4+\mathrm{C} 5$ compared to $\mathrm{C} 1+\mathrm{C} 2$ in IPP. It cannot, however, be the only factor, since fractionation at a single position is not likely to explain values of $\Delta_{\mathrm{i}}$ approaching $30 \%$ (see above).

The isotopic difference between phytol and its oxidation product from the photosynthetic non-sulfur bacterium $C$. aurantiacus is significantly smaller than that observed for algae and terrestrial plants (Table 2). Van der Meer et al. (2001) have investigated the stable carbon isotopic compositions of fatty acids and isoprenoid compounds from the same culture. Based on the isotopic composition of the $\mathrm{C}_{16}$ fatty acid and the isoprenoid verrucosanol, built via the MVA pathway (Rieder et al., 1998), they concluded that the carboxyl group of the original acetate building block was approximately $40 \%$ enriched in ${ }^{13} \mathrm{C}$ compared to the methyl group. Since phytol in C. aurantiacus is probably also made by the MVA pathway (phytol and verrucosanol are similarly depleted relative to the carbon source by $16.1 \pm 0.1$ and $17.6 \pm 0.4 \%$, respectively; Van der Meer et al., 2001), it follows that carbon atoms $\mathrm{C} 1+\mathrm{C} 2$ should on average be enriched in ${ }^{13} \mathrm{C}$ compared to $\mathrm{C} 3+\mathrm{C} 4+\mathrm{C} 5$. In turn, the oxidation product of phytol should be depleted in ${ }^{13} \mathrm{C}$. More specifically, using the data of van der Meer et al. (2001), we can calculate that the oxidation product of phytol should be depleted by $\sim 0.4 \%$ o. This predicted depletion is very close to the isotopic difference of $0.5 \pm 0.4 \%$ observed in this investigation and suggests that $\Delta_{\mathrm{g}}$ is negligible in this case. 
Phytol in E. gracilis is also expected to be a product of the MVA pathway (Disch et al., 1998; Kim et al., 2004). The expected isotopic consequences of this pathway have been discussed before (Hayes, 1993). Specifically, carbon atoms C1 and $\mathrm{C} 3$ are likely to be depleted in ${ }^{13} \mathrm{C}$ compared to $\mathrm{C} 2, \mathrm{C} 4$ and $\mathrm{C} 5$ (Fig. 1). This is mainly due to the depletion in ${ }^{13} \mathrm{C}$ of the carboxyl group of acetyl coenzyme A (Monson and Hayes, 1982a; Melzer and Schmidt, 1987). Accordingly, the average $\delta$ value for $\mathrm{C} 1+\mathrm{C} 2$ should be lower than that for $\mathrm{C} 3+\mathrm{C} 4+\mathrm{C} 5$. This is the opposite of what is observed for all algae and terrestrial plants, in agreement with the dominant use of the MEP pathway, but also the opposite of what is observed in E. gracilis. A possible explanation may be that our culturing conditions differed from those of the studies by Disch et al. (1998) and Kim et al. (2004), in which E. gracilis was grown strictly heterotrophically with only low illumination to avoid scrambling of the ${ }^{13} \mathrm{C}$-label. Indeed, Kim et al. (2004) showed that the MEP pathway is present in E. gracilis, but apparently involved only in the production of IPP used for carotenoid biosynthesis. This would be consistent with the evolutionary origin of the genus Euglena from a secondary endosymbiosis between a protist and a secondary green alga, the latter now forming the plastid of Euglena (Nozaki, 2005 and references cited therein). Possibly, the autotrophic growth conditions used in the present work have led to the use of a different IPP pool for the biosynthesis of phytol. Alternatively, the results for $E$. gracilis may indicate that biosynthetic pathways for IPP are not the major cause for the observed ${ }^{13} \mathrm{C}$-enrichment and that some other process, such as the formation of phytol, carotenoids, quinones and tocopherols from GGP (see below), has resulted in the ${ }^{13} \mathrm{C}$-enrichment of $\mathrm{C} 1+\mathrm{C} 2$ carbon atoms in phytol. 


\subsubsection{Fractionation during formation of phytol from GGP}

The pool of GGP, the direct precursor for phytol (Fig. 1), is used for both the biosynthesis of phytoene, the precursor for carotenoid biosynthesis, and the biosynthesis of phytol, which is, in turn, used for quinone and tocopherol biosynthesis (e.g. Ratledge and Wilkinson, 1989). If the tail-to-tail coupling of GGP to form phytoene is accompanied by isotopic fractionation, it will likely lead to depletions in ${ }^{13} \mathrm{C}$ at the $\mathrm{C} 1$ positions in the GGP flowing to phytoene. By mass balance, this will lead to an enrichment of ${ }^{13} \mathrm{C}$ at the $\mathrm{C} 1$ position in the remaining pool of GGP and hence to enrichment of ${ }^{13} \mathrm{C}$ in $\mathrm{C} 1$ of phytol esterified to chlorophyll (i.e., $\Delta_{\mathrm{g}}>0$ ). The magnitude of the enrichment will depend on the relative fluxes of GGP to phytoene and phytol which will, in turn, likely depend on the needs for phototrophy during growth of the organism. Variations of this sort may explain the observed range of ${ }^{13} \mathrm{C}$ enrichments at the $\mathrm{C} 1+\mathrm{C} 2$ carbon atoms in phytol.

As noted in the discussion of Figure 3, non-zero values of $\Delta_{g}$ are practically required to explain a significant portion of the observed range of values of $\Delta_{\mathrm{P}-\mathrm{K}}$. This indicates that the isotopic fractionations associated with the biosynthesis of carotenoids are substantial and that a substantial part of the flow of GGP is directed towards carotenoid biosynthesis. The relatively low enrichment at $\mathrm{C} 1+\mathrm{C} 2$ in phytol from $C$. aurantiacus may then not be due to different biosynthetic routes as suggested above, but to different flows of GGP directed towards the biosynthesis of carotenoids and bacteriochlorophylls.

Further work, especially intramolecular analyses with greater positional specificity, is needed to elucidate the exact roles of IPP biosynthesis and formation of phytol from GGP in the intramolecular distribution of ${ }^{13} \mathrm{C}$ within phytol. However, 
our results do suggest that the biosynthesis of phytol leads to a substantial intramolecular heterogeneity in ${ }^{13} \mathrm{C}$.

\subsection{Geochemical implications}

Diagenetic products of phytol, such as 2,6,10-trimethylpentadecan-2-one (e.g. Rontani et al., 1999) and phytane and pristane (e.g. Volkman and Maxwell, 1984 and references cited therein), are often encountered in recent and ancient sediments. Some of these products involve the loss of the $\mathrm{C} 1$ and/or $\mathrm{C} 2$ carbon atoms of phytol and hence their isotopic composition can be significantly different from that of their precursor. For instance, if pristane is formed from phytol, then our results suggest that pristane may be slightly depleted in ${ }^{13} \mathrm{C}$ relative to its $\mathrm{C}_{20}$ precursor. Hayes et al. (1990) and Kenig et al. (1994) compared the $\delta^{13} \mathrm{C}$ values of pristane and phytane in the Greenhorn formation and the Oxford Clay Formation, respectively, and found no significant difference between them. Data reported by Collister et al. (1994) for the Green River oil shale, Hughes et al. (1995) for a suite of source rocks, Logan et al. (1997) for Neoproterozoic and Early Cambrian sediments, van Kaam-Peters et al. (1998) for Kimmeridgian source rocks, Köster et al. (1998) for Oligocene source rocks and Grice et al. (1998) for Paleocene-Eocene lacustrine source rocks, also show no consistent or significant difference between the $\delta^{13} \mathrm{C}$ values of pristane and phytane. In contrast, Van Kaam-Peters and Sinninghe Damsté (1997) found pristane consistently depleted in ${ }^{13} \mathrm{C}$ by up to $1.5 \%$ o compared to sulfur-bound phytane in Jurassic S-rich sediments. Schouten et al. (2000a,b) measured the carbon isotopic compositions of pristane and phytane in Toarcian black shales and in sediments of the Miocene Monterey Formation. In these, pristane is consistently depleted in ${ }^{13} \mathrm{C}$ relative to phytane, by $0.7-1.5$ and by $0.4-2.5 \%$ for the Toarcian shales and Monterey 
sediments, respectively. A strong enrichment of ${ }^{13} \mathrm{C}$ in pristane relative to phytane has been reported only in rare cases (Freeman et al., 1989; Hughes et al., 1995). Thus, isotopic differences between pristane and phytane are generally either negligible or pristane is depleted by $0.5-2.5 \%$ in agreement with our prediction. It should, however, be noted that any observation of the predicted depletion in ${ }^{13} \mathrm{C}$ will depend on whether pristane and phytane are solely derived from phytol or if additional sources such as tocopherols and archaeal diether lipids with distinctly different ${ }^{13} \mathrm{C}$-contents are involved (Ten Haven et al., 1987; Koopmans et al., 1999). Koopmans et al. (1999) noted occasionally strong changes in $\delta^{13} \mathrm{C}$ values of pristane and phytane during thermal maturation, suggesting formation of these compounds from tocopherols and diether lipids present in higher molecular-weight fractions, i.e. asphaltenes and kerogen. Freeman et al. (1989) found a strong enrichment of ${ }^{13} \mathrm{C}$ in pristane versus phytane in the Messel oil shale and attributed this to an archaeal source for phytane. This mixing of sources for pristane and phytane could mask isotopic differences between these molecules caused by the intermolecular isotopic heterogeneity in the precursor molecule phytol.

Nevertheless, our data thus suggest that the stable carbon isotopic composition of sedimentary organic compounds that are diagenetically formed from one precursor may be dissimilar due to isotopic heterogeneity within molecules. Hence, isotopic differences between structurally similar molecules do not necessarily indicate different sources or isotopic fractionations due to diagenetic reactions. This is in contrast to earlier work where loss of methyl groups during aromatization of higher plant triterpenoids did not seem to result in large isotopic differences (Freeman et al., 1994). 


\section{Acknowledgements}

E. van Hunnick (University of Amsterdam) is thanked for culturing $T$. minimum and C. monoica, G. Fuchs and C. Menendez for culturing C. aurantiacus and A. Preisfeld (University of Bielefeld, Germany) for culturing E. gracilis. Shell International Petroleum Maatschappij BV is thanked for financial support for the irmGC-MS facility. Drs. Alex Sessions, Roger Summons and Philippe Schaeffer are thanked for their constructive comments on this manuscript.

\section{References}

Abelson, P. H., Hoering, T. C., 1961. Carbon isotope fractionation in formation of amino acids by photosynthetic organisms. Proceedings of the National Academy of Sciences 47, 623-632.

Bach Th. J., 1995. Some new aspects of isoprenoid biosynthesis- a review. Lipids 30, 191-202.

Collister, J.W., Summons, R.E., Lichtfouse, E., Hayes, J.M., 1992. An isotopic biogeochemical study of the Green River oil shale. In: Eckardt, C.B., Maxwell, J.R., larter, S.R., Manning, D.A.C., (Eds), Advances in Organic Geochemistry 1991. Organic Geochemistry 19, 265-276.

Cramer, M. Myers, J., 1952. Growth and photosynthetic characteristics of Euglena gracilis. Archives of Microbiology 17, 384-402.

Disch, A., Schwender, J., Muller, C., Lichtenthaler, H.K, Rohmer, M., 1998. Distribution of the mevalonate and glyceraldehyde phosphate/pyruvate pathways for isoprenoid biosynthesis in unicellular algae and the cyanobacterium Synechocystis PCC 6714. Biochemistry Journal 333, 381-388. 
Eisenreich, W., Bacher, A., Arigoni, D., Rohdich, F., 2004. Biosynthesis of isoprenoids via the non-mevalonate pathway. Cellular and Molecular Life Sciences 61, 1401-1426.

Freeman, K.H., Hayes, J.M., Trendel, J.M., Albrecht, P., 1989. Evidence from carbon isotope measurements for diverse origins of sedimentary hydrocarbons. Nature $343,254-256$.

Freeman, K.H, Boreham, C.J., Summons, R.E., Hayes, J.M., 1994. The effect of aromatization on the isotopic compositions of hydrocarbons during early diagenesis. Organic Geochemistry 21, 1037-1049.

Grice, K., Schouten S., Peters K.E., Sinninghe Damsté, J.S., 1998. Molecular isotopic characterisation of hydrocarbon biomarkers in Palaeocene-Eocene- evaporitic, lacustrine source rocks from the Jianghan Basin, China. In: Horsfield, B., Radke, M., Schaefer, R.G., Wilkes H., (Eds.), Advances in Organic Geochemistry 1997, Organic Geochemistry 29, 1745-1764

Guillard, R.R.L., 1975. Culture of phytoplankton for feeding marine invertebrates. In:. Smith W.L., Chanley M.H. (Eds.), Culture of marine invertebrate animals Plenum Press, New York, pp. 29-60.

Hansen, P.J., 1989. The red tide dinoflagellate Alexandrium tamarense: effects on behaviour and growth of a tintinnid ciliate. Marine Ecology Progress Series 53, 105-116.

Ten Haven, H.L., De Leeuw, J.W., Rullkötter J., Sinninghe Damsté, J.S., 1987. Restricted utility of the pristane/phytane ratio as a palaeoenvironmental indicator? Nature 330, 641-643.

Hayes, J.M., 1993. Factors controlling the ${ }^{13} \mathrm{C}$ contents of sedimentary organic compounds: Principles and evidence. Marine Geology 113, 111-125. 
Hayes, J.M., 2001. Fractionation of the isotopes of carbon and hydrogen in biosynthetic processes In: Valley, J.W., Cole, D.R., (Eds.), Stable Isotope Geochemistry. The Mineralogical Society of America, Washington, pp. 225-277.

Hayes, J.M., Freeman, K.H., Popp, B.N., Hoham, C.H., 1990. Compound-specific isotope analysis: A novel tool for reconstruction of ancient biogeochemical processes. In: Durand B., Behar F., (Eds.), Advances in Organic Geochemistry 1989. Organic Geochemistry 16, 1115-1128.

Hughes, W.B, Holba, A. G, Dzou L.I.P, 1995. The ratios of dibenzothiophene to phenanthrene and pristane to phytane. Geochimica et Cosmochimica Acta 59, 3581-3598.

van Kaam-Peters, H.M.E., Sinninghe Damsté, J.S., 1997. Characterisation of an extremely organic sulfur-rich, 150 Ma old carbonaceous rock: Palaeoenvironmental implications. Organic Geochemistry 27, 371-397.

van Kaam-Peters, H.M.E., Schouten, S., Köster, J., Sinninghe Damsté, J.S., 1998. Controls on the molecular and carbon isotopic composition of organic matter deposited in a Kimmeridgian euxinic shelf sea: Evidence for preservation of carbohydrates through sulfurisation. Geochimica et Cosmochimica Acta 62, 3259-3283.

Kates, J.R., Jones, R.F., 1964. The control of gametic differentiation in liquid cultures of Chlamydomonas. Journal of Cellular and Comparative Physiology, 63, 157-164.

Kenig, F., Hayes, J.M., Popp, B.N., Summons, R.E., 1994. Isotopic biogeochemistry of the Oxford Clay Formation (Jurassic), UK. Journal of the Geological Society, London 151, 139-152. 
Kim, D., Filtz, M.R., Proteau, P.J., 2004. The methylerythritol phosphate pathway contributes to carotenoid but not phytol biosynthesis in Euglena gracilis. Journal of Natural Products 67, $1067-1069$.

Kohnen, M.E.L., Schouten, S., Sinninghe Damsté, J.S., de Leeuw, J.W., Merritt, D.A. , Hayes, J.M., 1992. Recognition of paleobiochemicals by a combined molecular sulfur and isotope geochemical approach. Science 256, 358-362.

Koopmans, M.P., Rijpstra, W.I.C., Klapwijk, M.M., de Leeuw, J.W., Lewan, M.D., Sinninghe Damsté, J.S., 1999. A thermal and chemical degradation approach to decipher pristane and phytane precursors in sedimentary organic matter. Organic Geochemistry 19, 1089-1104.

Köster, J., Rospondek, M., Schouten, S., Kotarba, M., Zubrzycki, A., De Leeuw J.W., Sinninghe Damsté J.S., 1998. Biomarker geochemistry of a foreland basin: the Oligocene Menilite Formation in SE Poland. In: Horsfield, B., Radke, M., Schaefer, R.G., Wilkes H. (Eds.), Advances in Organic Geochemistry 1997, Organic Geochemistry 29, 649-669.

Lichtenthaler, H.K., 1999. The 1-deoxy-d-xylulose-5-phosphate pathway of isoprenoid biosynthesis in plants. Annual Review in Plant Physiology and Plant Molecular Biology 50, 47-65.

Lichtenthaler, H.K., Schwender, J., Disch, A., Rohmer, M., 1997. Biosynthesis of isoprenoids in higher plant chloroplasts proceeds via a non-mevalonate pathway. FEBS Letters 400, 271-274.

Logan, G.A., Summons, R.E., Hayes, J.M., 1997. An isotopic biogeochemical study of Neoproterozoic and Early Cambrian sediments from the Centralian Superbasin, Australia. Geochimica et Cosmochimica Acta 61, 5391-5409. 
Massé, G., Belt, S.T., Rowland, S.J., Rohmer, M., 2004. Isoprenoid biosynthesis in the diatoms Rhizosolenia setigera (Brightwell) and Haslea ostrearia (Simonsen). Proceedings of the National Academy of Sciences 101, 4413-4418.

van der Meer, M.T.J., Schouten, S., Sinninghe Damsté, J.S., 1998. The effect of the reversed tricarboxylic acid cycle on the ${ }^{13} \mathrm{C}$ contents of bacterial lipids. Organic Geochemistry 28, 527-533.

van der Meer, M.T.J., Schouten, S., Van Dongen, B.E., Rijpstra, W.I.C., Fuchs, G., Sinninghe Damsté, J.S., de Leeuw, J.W., Ward, D.M., 2000. Biosynthetic controls on the ${ }^{13} \mathrm{C}$-contents of organic components in the photoautotrophic bacterium Chloroflexus aurantiacus. Journal of Biological Chemistry 276, 10971-10976.

Melzer, E., Schmidt, H.-L., 1987. Carbon isotope effects on the pyruvate dehydrogenase reaction and their importance for relative carbon-13 depletion in lipids. Journal of Biological Chemistry 262, 8159-8164.

Menendez, C., Bauer, Z., Huber, H., Gad'on, N., Stetter, K. O., Fuchs G., 1999. Presence of acetyl coenzyme A (CoA) carboxylase and propionyl-CoA carboxylase in autotrophic Crenarchaeota and indication for operation of a 3hydroxypropionate cycle in autotrophic carbon fixation. Journal of Bacteriology 181, 1088-1098.

Monson, K.D., Hayes, J.M., 1982a. Carbon isotope fractionations in the synthesis of bacterial fatty acids. Ozonolysis of unsaturated fatty acids as a means of determining the intramolecular distribution of carbon isotopes. Geochimica et Cosmochimica Acta 46, 139-149.

Monson, K. D., Hayes, J. M., 1982b. Biosynthetic control of the natural abundance of carbon 13 at specific position within fatty acids in Saccharomyces cerevisiae. 
Isotope fractionations in lipid synthesis as evidence for peroxisomal regulation. Journal of Biological Chemistry 257, 5568-5575.

Nes, W.R., McKean, M.L., 1977. Biochemistry of steroids and other isopentoids University Park Press, Baltimore, pp. 690.

Nozaki, H., 2005. A new scenario of plastid evolution: plastid primary endosymbiosis before the divergence of the "Plantae," emended. Journal of Plant Research $118,247-255$.

Ratledge, C., Wilkinson, S.G., 1989. Microbial lipids. Academic Press, London, pp. 726.

Ricci, M. P., Merritt, D. A., Freeman, K. H., Hayes, J. M., 1994. Acquisition and processing of isotope ratio monitoring mass spectroscopic data. Organic Geochemistry 21, 561-571.

Rieder, C., Strauß, G., Fuchs, G. , Arigoni, D., Bacher, A., Eisenreich, W., 1998. Biosynthesis of the diterpene verrucosan-2 $\beta$-ol in the phototrophic eubacterium Chloroflexus aurantiacus. Journal of Biological Chemistry 273, 18099-18108.

Rohmer, M, Knani, M, Simonin, P. Sutter, B., Sahm, H., 1993. Isoprenoid biosynthesis in bacteria: a novel pathway for the early steps leading to isopentyl diphosphate. Biochemistry Journal 295, 517-524.

Rohmer, M., Seemann, M., Horbach, S., Bringer-Meyer, S., Sahm, H., 1996. Glyceraldehyde 3-phosphate and pyruvate as precursors of isoprenic units in an alternative non-mevalonate pathway for terpenoid biosynthesis. Journal of the American Chemical Society 118, 2564-2566.

Rohmer, M., 2007. Mevalonate-independent methylerythritol phosphate pathway for isoprenoid biosynthesis. Elucidation and distribution. Pure and Applied Chemistry $75,375-387$. 
Rontani, J-F, Bonin, P.C., Volkman, J.K., 1999. Biodegradation of free phytol by bacterial communities isolated from marine sediments under aerobic and denitrifying conditions. Applied and Environmental Microbiology 65, 54845492.

Sakata, S., Hayes, J.M., McTaggart, A.R., Evans, R.A., Leckrone, K.J., Togasaki, R.K., 1997. Carbon isotopic fractionation associated with lipid biosynthesis by a cyanobacterium: Relevance for interpretation of biomarker records. Geochimica et Cosmochimica Acta 61, 5379-5389.

Schouten, S., Moerkerken, P., Gelin, F., Baas, M., De Leeuw, J.W., Sinninghe Damsté J.S., 1998a. Structural characterisation of aliphatic, non-hydrolyzable biopolymers in freshwater algae and a leaf cuticle by ruthenium tetroxide degradation. Phytochemistry 49, 987-993.

Schouten, S., Klein, Breteler, W., Blokker, P., Schogt, N., Rijpstra, W.I.C., Grice, K., Baas, M., Sinninghe Damsté, J.S., 1998b. Biosynthetic effects on the stable carbon isotopic compositions of algal lipids: Implications for deciphering the carbon isotopic biomarker record. Geochimica et Cosmochimica Acta 62, 13971406.

Schouten, S., Schoell, M., Summons, R.E., Sinninghe Damsté, J.S., De Leeuw J.W., 2000a. Molecular biogeochemistry of Monterey sediments (Naples Beach, USA) II: Stable carbon isotopic compositions of free and sulphur-bound carbon skeletons. In: Isaacs, C.M., Rullkötter J., (Eds.), The Monterey Formation: From Rock to Molecule. Columbia University Press, pp. 175-188.

Schouten, S., van Kaam-Peters H.M.E., Schoell, M., Sinninghe Damsté, J.S., 2000b. Effects of an oceanic anoxic event on Early Toarcian carbon. American Journal of Science 300, 1-22. 
Schwender, J., Gemünden, C., Lichtenthaler, H.K., 2001. Chlorophyta exclusively use the 1-deoxyxylulose 5-phosphate/2-C-methylerythritol 4-phosphate pathway for the biosynthesis of isoprenoids. Planta 212, 416-423.

Summons, R.E., Jahnke, L.L., Roksandic, Z., 1994. Carbon isotopic fractionation in lipids from methanotrophic bacteria: Relevance for interpretation of the geochemical record of biomarkers. Geochimica et Cosmochimica Acta 58, 2853-2863.

Volkman, J.K., Maxwell J.R., 1984. Acyclic isoprenoids as biological markers. In: Johns, R.B. (Ed.), Biological markers in the sedimentary record, Elsevier, Amsterdam, pp. 1-42. 
Table 1. Investigated algae, terrestrial plants and bacteria and their culture conditions.

\begin{tabular}{|c|c|c|c|c|}
\hline Organisms & Class & $\begin{array}{l}\text { Culture } \\
\text { type }\end{array}$ & $\begin{array}{l}\mathrm{T} \\
\left({ }^{\circ} \mathrm{C}\right)\end{array}$ & $\mathrm{CO}_{2}$ source \\
\hline \multicolumn{5}{|l|}{ Freshwater algae } \\
\hline Tetraedron minimum (c) & Chlorophyceae & Continuous & 19 & $\mathrm{Air}+2 \% \mathrm{CO}_{2}$ \\
\hline Tetraedron minimum (b) & Chlorophyceae & Batch & 19 & $\mathrm{Air}+2 \% \mathrm{CO}_{2}$ \\
\hline Scenedesmus communis & Chlorophyceae & Batch & 19 & $\mathrm{Air}+2 \% \mathrm{CO}_{2}$ \\
\hline Chlamydomonas monoica & Chlorophyceae & Continuous & 19 & $\mathrm{Air}+2 \% \mathrm{CO}_{2}$ \\
\hline Pediastrum boryanum & Chlorophyceae & Batch & 19 & $\mathrm{Air}+2 \% \mathrm{CO}_{2}$ \\
\hline Euglena gracilis & Euglenophyceae & Batch & 30 & $\mathrm{Air}+5 \% \mathrm{CO}_{2}$ \\
\hline \multicolumn{5}{|l|}{ Marine algae } \\
\hline$\overline{\text { Dunaliella sp. }}$ & Chlorophyceae & Continuous & 15 & Air \\
\hline Tetraselmis sp. & Prasinophyceae & Continuous & 15 & Air \\
\hline Thalassiosira weissflogii & Bacillariophyceae & Continuous & 15 & Air \\
\hline Amphidinium sp. & Dinophyceae & Continuous & 15 & Air \\
\hline Nannochloropsis salina & Eustigmatophycae & Batch & 15 & Air \\
\hline \multicolumn{5}{|l|}{ Terrestrial plants } \\
\hline$\overline{\text { Sphagnum recurvum }}$ & Bryophyta & Natural & n.a. & Air \\
\hline Sphagnum compactum & Bryophyta & Natural & n.a. & Air \\
\hline Eriophorum vaginatum & Cyperaceae & Natural & n.a. & Air \\
\hline Ficus benjamini & Moraceae & Natural & $\mathrm{rT}$ & Air \\
\hline$\underline{\text { Photosynthetic bacteria }}$ & & & & \\
\hline$\overline{\text { Chloroflexus aurantiacus }}$ & Green non-sulfur & Batch & rT & Air \\
\hline
\end{tabular}

(c) $=$ continuous culture

(b) = batch culture

n.a. = not applicable

rT $=$ room temperature 
Table 2. Stable carbon isotopic composition of phytol $\left(\delta_{\mathrm{P}}\right)$ and its oxidation product $\left(\delta_{\mathrm{K}}\right)$ in algae, terrestrial plants and bacteria. Uncertainties are standard deviations on the means of the indicated numbers of replicates (see methods).

\begin{tabular}{|c|c|c|c|}
\hline Organisms & $\overline{\delta_{\mathrm{P}}}(\% o)$ & $\overline{\delta_{\mathrm{K}}}(\% o)$ & $\begin{array}{c}\Delta_{\mathrm{P}-\mathrm{K}}^{\mathrm{a}} \\
(\%)\end{array}$ \\
\hline Synthetic phytol & $-32.3 \pm 0.4(3)$ & $-32.1 \pm 0.4(2)$ & $-0.2 \pm 0.5$ \\
\hline \multicolumn{4}{|l|}{ Freshwater algae } \\
\hline Tetraedron minimum & & & \\
\hline continuous culture 1 & $-30.0 \pm 0.4(3)$ & $-31.5 \pm 0.3(3)$ & $+1.6 \pm 0.5$ \\
\hline continuouis culture 2 & $-29.8 \pm 0.4(3)$ & $-31.9 \pm 0.4(2)$ & $+2.1 \pm 0.5$ \\
\hline batch culture & $-53.2 \pm 0.4(3)$ & $-54.4 \pm 0.3(3)$ & $+1.3 \pm 0.5$ \\
\hline Scenedesmus communis & $-45.2 \pm 0.4(3)$ & $-48.5 \pm 0.3(3)$ & $+3.2 \pm 0.5$ \\
\hline Chlamydomonas monoica & $-49.1 \pm 0.4(3)$ & $-50.9 \pm 0.3(3)$ & $+1.7 \pm 0.5$ \\
\hline Pediastrum boryanum & $-41.2 \pm 0.4(3)$ & $-45.3 \pm 0.3(3)$ & $+4.1 \pm 0.5$ \\
\hline Euglena gracilis & $-56.9 \pm 0.4(3)$ & $-58.7 \pm 0.3(2)$ & $+1.7 \pm 0.5$ \\
\hline \multicolumn{4}{|l|}{ Marine algae } \\
\hline Dunaliella sp. & $-24.5 \pm 0.4(3)$ & $-26.3 \pm 0.4(2)$ & $+1.7 \pm 0.5$ \\
\hline Tetraselmis sp. & $-17.5 \pm 0.4(3)$ & $-21.0 \pm 0.3(4)$ & $+3.5 \pm 0.5$ \\
\hline Thalassiosira weissflogii & $-21.7 \pm 0.4(3)$ & $-23.0 \pm 0.3(3)$ & $+1.3 \pm 0.5$ \\
\hline Amphidinium sp. & $-35.1 \pm 0.4(3)$ & $-38.0 \pm 0.3(3)$ & $+3.0 \pm 0.5$ \\
\hline Nannochloropsis salina & $-4.6 \pm 0.4(3)$ & $-5.9 \pm 0.3(3)$ & $+1.3 \pm 0.5$ \\
\hline \multicolumn{4}{|l|}{$\underline{\text { Terrestrial plants }}$} \\
\hline$\overline{\text { Sphagnum recurvum }}$ & $-35.5 \pm 0.4(4)$ & $-39.1 \pm 0.4(2)$ & $+3.6 \pm 0.5$ \\
\hline Sphagnum compactum & $-33.1 \pm 0.4(3)$ & $-35.5 \pm 0.4(2)$ & $+2.4 \pm 0.5$ \\
\hline Eriophorum vaginatum & $-32.0 \pm 0.4(3)$ & $-34.3 \pm 0.4(2)$ & $+2.3 \pm 0.5$ \\
\hline Ficus benjamini & $-31.2 \pm 0.4(3)$ & $-34.9 \pm 0.4(2)$ & $+3.8 \pm 0.5$ \\
\hline Photosynthetic bacteria & & & \\
\hline Chloroflexus aurantiacus & $-52.8 \pm 0.4(4)$ & $-53.3 \pm 0.3(4)$ & $+0.5 \pm 0.5$ \\
\hline
\end{tabular}

${ }^{\mathrm{a}} \Delta_{\mathrm{P}-\mathrm{K}}=\overline{\delta_{\mathrm{P}}}-\overline{\delta_{\mathrm{K}}}$ 


\section{Figure captions}

Fig. 1 Schematic representation of the MVA-pathway and MEP-pathway for IPP biosynthesis and biosynthesis of chlorophyll, carotenoids, quinones and tocopherols (after Lichtenthaler, 1999, Eisenreich et al., 2004, Rohmer 2007 and Ratledge and Wilkinson, 1989). Both start with pyruvate (indicated by the left square) and end with phytol (indicated by the right square). Only one GGP pool is drawn but there may be multiple pools of GGP inside the chloroplast (Ratledge and Wilkinson, 1989).

Fig. 2 Formation of phytol from IPP, followed by $\mathrm{RuO}_{4}$ oxidation of phytol leading to the formation of 6,10,14-trimethylpentadecan-2-one.

Fig. 3 Graph indicating combinations of $\Delta_{\mathrm{i}}$ and $\Delta_{\mathrm{g}}$ consistent with observed values of $\Delta_{\mathrm{P}-\mathrm{K}}$. Since neither $\Delta_{\mathrm{i}}$ nor $\Delta_{\mathrm{g}}$ is likely to exceed $30 \%$ o, the observed values of $\Delta_{\mathrm{P}-\mathrm{K}}$ are probably explained by combination of fractionations associated with the production of IPP $\left(\Delta_{\mathrm{i}}\right)$ and with the division of GPP between phytol and carotenoid products $\left(\Delta_{\mathrm{g}}\right)$. 


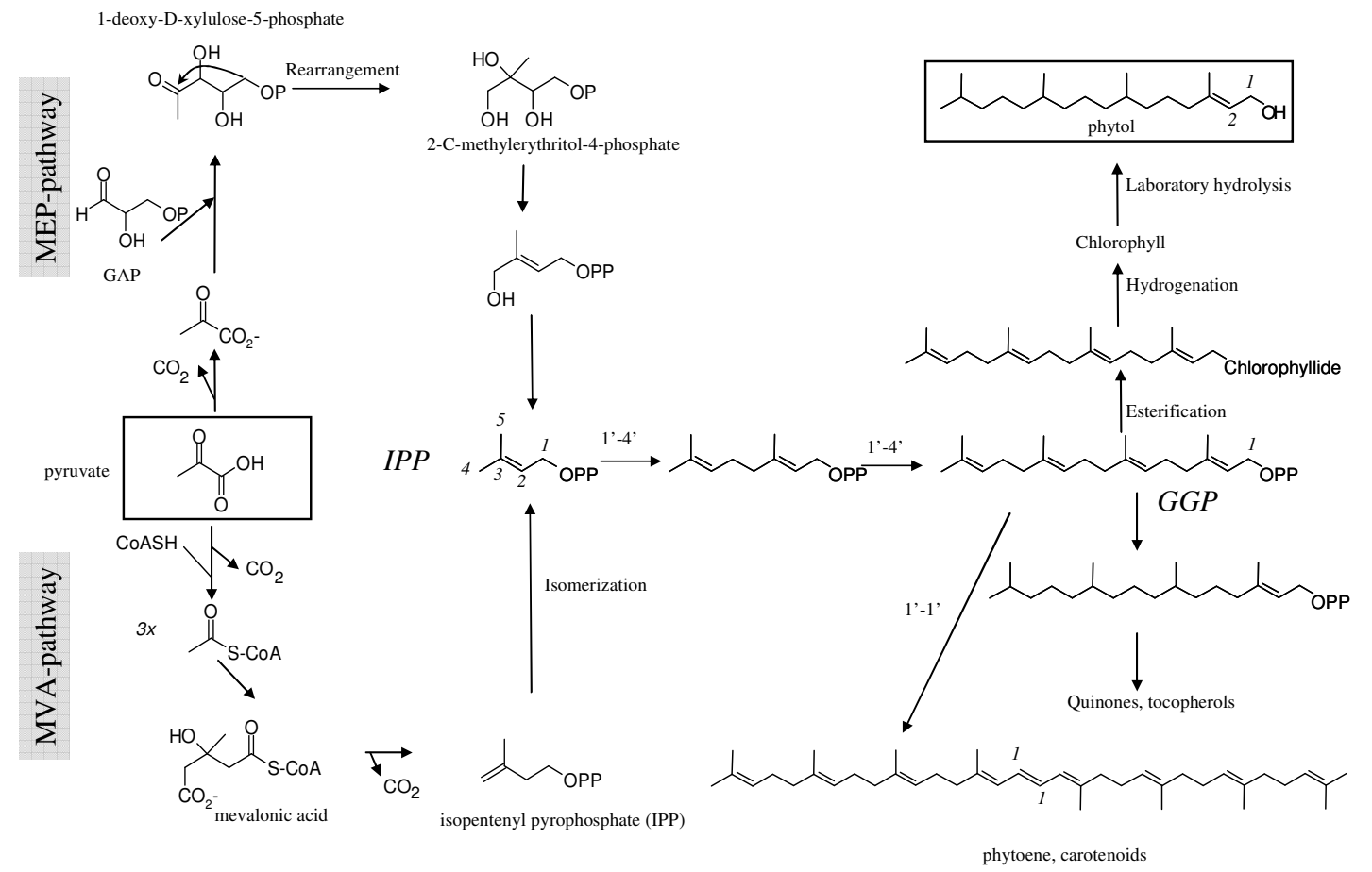




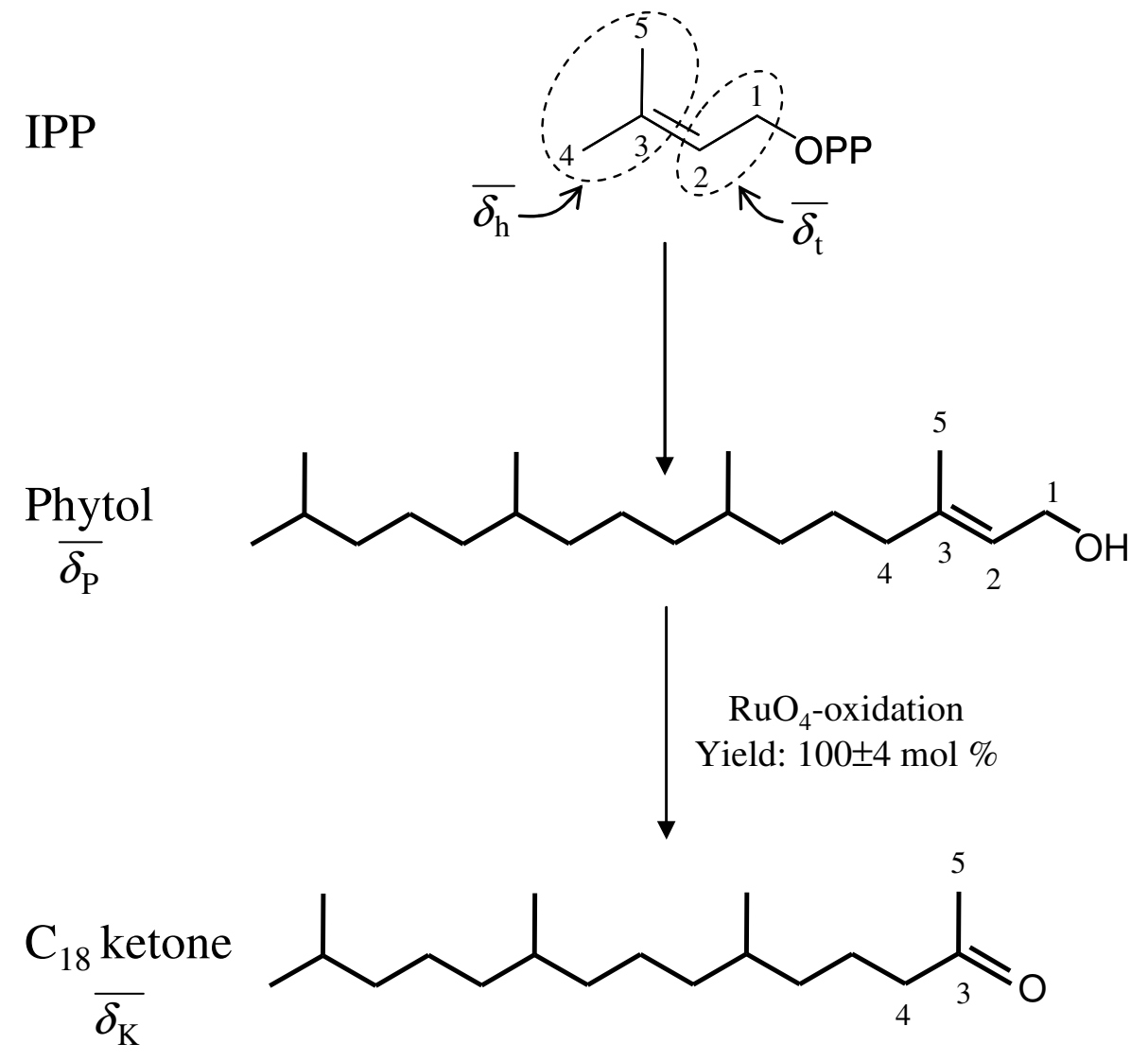




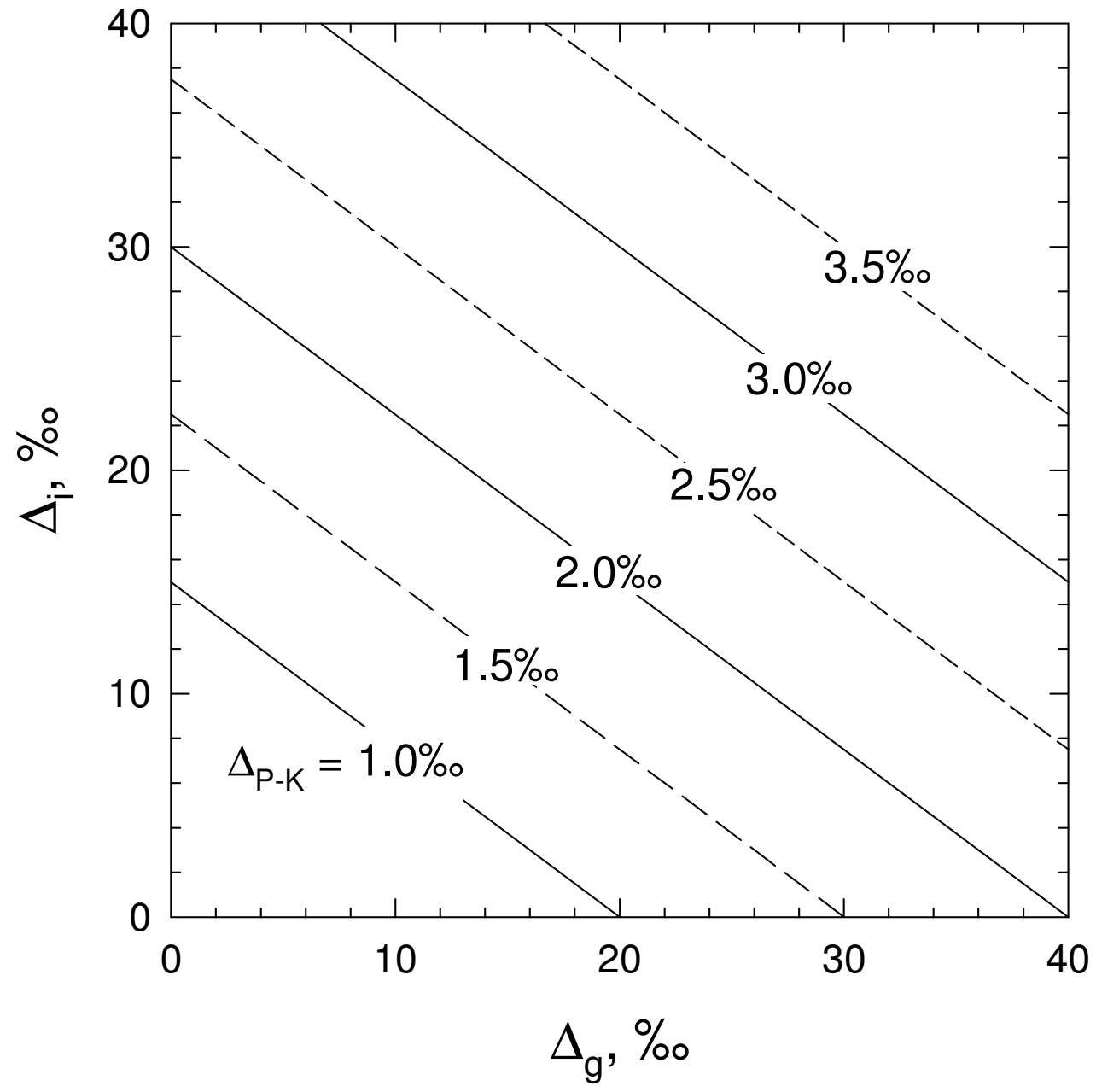

